\title{
A routine third trimester growth ultrasound in the obese pregnant woman does not reliably identify fetal growth abnormalities:
}

A retrospective cohort study.

\section{Dr Aekta NEEL,}

Specialist Obstetrician and Gynaecologist,

Women's and Children's Division,

Joan Kirner Women's and Children's at Sunshine Hospital,

Western Health, St Albans, Victoria 3021,

aekta.neel@wh.org.au

Corresponding author - ORCID: https://orcid.org/0000-0002-9969-4131

Financial support - NIL

\section{Dr Chris E CUNNINGHAM}

Honorary Research Fellow

Rural Health

The University of Melbourne

christine.cunningham@unimelb.edu.au

ORCID: https://orcid.org/0000-0002-9838-0325

Financial support - NIL

\section{A Prof Glyn R TEALE,}

Clinical Services Director,

Women's and Children's Division,

Joan Kirner Women's and Children's at Sunshine Hospital,

This is the author manuscript accepted for publication and has undergone full peer review but has not been through the copyediting, typesetting, pagination and proofreading process, which may lead to differences between this version and the Version of Record. Please cite this article as doi: $10.1111 / \mathrm{AJO} 0.13256$

This article is protected by copyright. All rights reserved 
Western Health, St Albans, Victoria 3021,

glyn.teale@wh.org.au

ORCID: https://orcid.org/0000-0002-6304-0849

Financial support - NIL

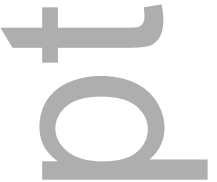

Keywords: obesity, ultrasound, estimated fetal weight, birthweight percentile, sensitivity

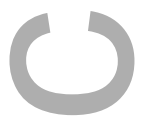

Word Count (excluding abstract, references, figures, \& tables): 2349

Abstract: + Keywords: 242

Figure count: 2

Table count: 2

No authors have a conflict of interest to declare as per the ANZJOG policy outlined at https://obgyn.onlinelibrary.wiley.com/hub/journal/1479828X/about/author-guidelines

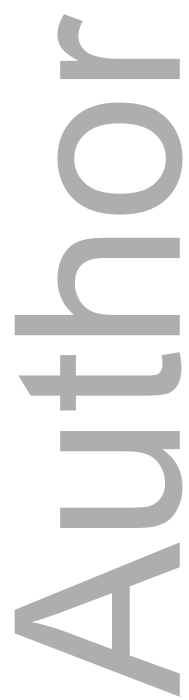


DR. AEKTA NEEL (Orcid ID : 0000-0002-9969-4131)

Article type : Original Manuscript

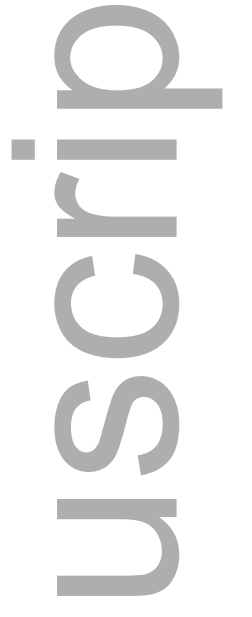

A routine third trimester growth ultrasound in the obese pregnant woman does not reliably identify fetal growth abnormalities:

A retrospective cohort study.

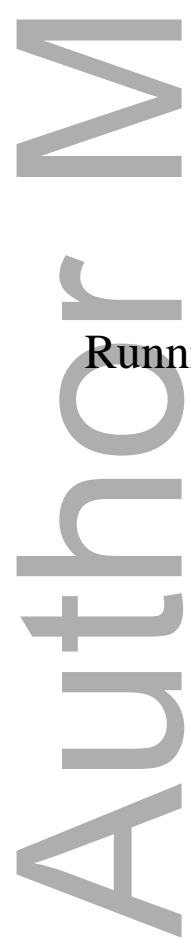


Keywords: obesity, ultrasound, estimated fetal weight, birthweight percentile, sensitivity

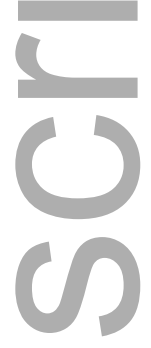

Word Count (excluding abstract, references, figures, \& tables): 2349

Abstract: + Keywords: 242

Figure count: 2

Table count: 2

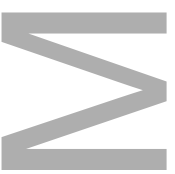

$\underline{\text { Abstract }}$

\section{Background}

In response to the challenges of assessing fetal growth in obese women, guidelines recommend routine third trimester ultrasound scans.

\section{Aim}

The aim of this study was to assess the diagnostic performance of this routine scan in obese women $\left(\mathrm{BMI} \geq 35 \mathrm{~kg} / \mathrm{m}^{2}\right)$.

\section{Methods}

A retrospective cohort study of 1008 pregnancies with maternal BMI $\geq 35 \mathrm{~kg} / \mathrm{m}^{2}$ born after 37 weeks' gestation at a Victorian hospital from 2015 - 2017. Multiple pregnancies 
and those affected by diabetes were excluded. Growth ultrasounds were performed between $34+0$ and $36+6$ weeks' gestation. Sensitivity, specificity, positive predictive value (PPV) and negative predictive value (NPV) for the detection of large for gestational age (LGA >90\%) and small for gestational age (SGA <10\%) were calculated using ultrasound estimated fetal weight (EFW) or abdominal circumference (AC) and compared with gestational age and gender-based birthweight percentiles.

\section{Results}

Using EFW, sensitivity for detecting SGA at birth was 8.1\% (6 of 74) with a PPV of $100 \%$. Sensitivity for detecting LGA at birth was 61.0\% (119 of 195), PPV 54.8\%.

Sensitivity, specificity, PPV and NPV percentages were all lower using AC. Only $40 \%$ of actual birthweight percentiles (405/1008) were within $+/-10$ percentiles of their growth ultrasound EFW percentile.

\section{Conclusion}

The performance of a routine third trimester ultrasound in women with BMI $\geq 35 \mathrm{~kg} / \mathrm{m}^{2}$ suggests limited utility in helping identify aberrant fetal growth. This has important implications for the management of obese pregnant women.

Keywords: obesity, ultrasound, estimated fetal weight, birthweight percentile, sensitivity

\section{Introduction}

Obesity has become an increasing challenge in obstetric practice and is now considered to be the most common co-morbidity in pregnancy. ${ }^{1,2}$ Australian obesity rates are rising with $46 \%$ of pregnant women either overweight (Body mass index [BMI] $25-30 \mathrm{~kg} / \mathrm{m}^{2}$ ) or obese $\left(\mathrm{BMI}>30 \mathrm{~kg} / \mathrm{m}^{2}\right){ }^{3}$ Obesity is known to increase almost all adverse pregnancy outcomes and has impacts on maternal, fetal and neonatal health. ${ }^{1,2,4}$

Extremes of fetal growth, namely small for gestational age (SGA; birthweight less than the $10^{\text {th }}$ percentile) and large for gestational age (LGA; birthweight greater than the $90^{\text {th }}$ percentile), are more common in obese pregnant women and may, at least in part, explain the increased rates of stillbirth, shoulder dystocia, caesarean section and birth trauma. ${ }^{5}$ 
Accurate assessment of fetal size is challenging in overweight and obese women where clinical assessment is unreliable, particularly at the extremes of BMI. The Royal Australian and New Zealand College of Obstetricians and Gynaecologists recommends offering a third trimester fetal growth ultrasound to obese women. ${ }^{6}$ In Victoria, the statewide guideline on obesity in pregnancy recommends, as a minimum, a routine third trimester ultrasound at 35 weeks for women with Class II (BMI $35-39.9 \mathrm{~kg} / \mathrm{m}^{2}$ ) or Class III (BMI $40 \geq \mathrm{kg} / \mathrm{m}^{2}$ ) obesity. ${ }^{7}$

While it is well established that maternal obesity has a detrimental effect on the ultrasound detection of fetal anomalies, ${ }^{1}$ there is conflicting evidence on whether obesity impacts the accuracy of ultrasound fetal weight estimation. ${ }^{8-11}$ Many studies that look at accuracy of fetal weight estimation have compared measurements (in grams) taken shortly prior to delivery (i.e. within 7 days) with actual birth weight. These studies have been reassuring in terms of accuracy but do not necessarily reflect general clinical practice where routine scans for fetal size are commonly undertaken weeks prior to delivery.

In 2011, our institution adopted the Victorian state-wide recommendation of routine ultrasounds for women with Class II and III obesity at 35 weeks' gestation. In this study we evaluate whether the estimated fetal weight (EFW) and abdominal circumference (AC) percentiles on a 35 week ultrasound scan is predictive of the eventual birthweight percentile, whether this varies by BMI over $35 \mathrm{~kg} / \mathrm{m}^{2}$ and the clinical utility of this ultrasound in detecting SGA and LGA.

\section{Materials and Methods}

This was a retrospective cohort study derived from a convenience sample performed at a major metropolitan hospital in Victoria, Australia from 1 January 2015 to 31 December 2017. Ethics approval was obtained from the ethics committee of Western Health (WH Q2016.61).

Our hospital protocol dictates that all women with a BMI $\geq 35 \mathrm{~kg} / \mathrm{m}^{2}$ have at least one growth ultrasound at approximately 35 weeks to screen for abnormalities of fetal growth as recommended in the Victorian guideline. Women were included if they had a BMI $\geq 35$ 
$\mathrm{kg} / \mathrm{m}^{2}$ with a singleton pregnancy and livebirth at or after $37+0$ weeks gestation and had an ultrasound performed between $34+0$ and $36+6$ weeks' gestation. Pregnancies complicated by diabetes (both gestational or pre-gestational) were excluded, as diabetes is known to cause alterations in fetal growth ${ }^{12}$ and is an indication for a growth ultrasound at our institution. We recorded the total number of third trimester scans for each woman and if more than one scan was performed between $34+0$ and $36+6$, the latest scan was used for analysis.

Women were identified using the Birthing Outcome System (BOS), which provided information on BMI at booking visit, gravida and parity, medical and obstetric history, gestational age, delivery date, birthweight and sex. Details of ultrasounds were obtained directly from radiological reports to minimize the likelihood of transcription error and included the date and gestation of ultrasound, estimated fetal weight in grams and as a percentile, and abdominal circumference measurement as a percentile. While most women had their ultrasounds performed at the hospital, we accepted external ultrasounds if the report was accessible in the medical records. All ultrasounds performed in the hospital used the Hadlock formula in calculating the $\mathrm{EFW} ;{ }^{13}$ the formula used by non-hospital providers was not known in all cases.

Birthweight percentiles were calculated based on gestation and gender, although not adjusted for ethnicity or maternal height/weight, as our hospital does not use customized growth charts. The birthweight was converted to a percentile using an online "Generic Birthweight Centile Calculator" from The Perinatal Institute ${ }^{14}$ into which a population average birthweight at term can be entered. We used the "Australian national birthweight percentiles by sex and gestational age" for the population average birthweight. ${ }^{15}$

Women were stratified by BMI group: Class II (BMI 35.0-39.9 kg/m²); Class III (BMI $\geq 40$ $\mathrm{kg} / \mathrm{m}^{2}$ ); all women (Class II/III combined). Chi-square tests were used to assess for differences in parity, number of ultrasound scans performed and percentage of SGA and LGA by BMI class. A one way between groups analysis of variance was conducted to explore the impact of BMI class on birthweight percentile. Sensitivity, specificity, positive predictive and negative predictive values and $95 \% \mathrm{CI}$ were calculated using the EFW and AC percentile to predict birth SGA and LGA. We further analysed the predictive value of the EFW in predicting the birthweight within $+/-10$ percentiles. Sample size and power was 
assessed as acceptable as outlined by Bujang and Adnan. ${ }^{16}$ All analyses were performed using IBM SPSS v 22 and Varsstats.

\section{$\underline{\text { Results }}$}

From $2015-2017$, there were 16,058 deliveries, and of these 2036 had a maternal booking $\mathrm{BMI} \geq 35 \mathrm{~kg} / \mathrm{m}^{2}$ (12.6\%). There were 1257 pregnancies that met the study inclusion criteria of a singleton, term delivery without diabetes. Seven percent $(n=89)$ had no ultrasound scan performed; many of these women had minimal antenatal care or presented 'unbooked'. Ninety three percent had a third trimester ultrasound, although $7.5 \%$ had a scan prior to $34+0$ and $5.5 \%$ had a sean after $36+6$. A total of 1008 women $(80 \%)$ had at least one growth ultrasound performed between $34+0$ and 36+6 weeks, compliant with hospital policy and were included for analysis (Figure 1); $52.1 \%$ were Class II obese and $47.9 \%$ were Class III obese $\left(31.1 \%\right.$ had BMI $40-45.9 \mathrm{~kg} / \mathrm{m}^{2}, 11.3 \%$ had BMI $45-49.9 \mathrm{~kg} / \mathrm{m}^{2}$ and $5.5 \%$ had BMI $\geq$ $\left.50 \mathrm{~kg} / \mathrm{m}^{2}\right)$.

Only $3 \%$ of ultrasounds were undertaken by an external provider, while $60 \%$ of women had more than one growth scan. Class III obesity was associated with a higher number of third trimester growth ultrasounds performed $(\mathrm{p}<0.001)$ and an earlier gestation at delivery $(\mathrm{p}=0.002)$, with no significant difference in mean birthweight (Table 1).

Seventy four of the 1008 pregnancies analysed resulted in the birth of a SGA neonate. Using EFW, 6 cases of SGA were reported on ultrasound (EFW $<10^{\text {th }}$ percentile) and all of these neonates had birthweight below the $10^{\text {th }}$ percentile (Table 2). Using EFW to detect SGA had a sensitivity of $8.1 \%$, specificity and positive predictive value $100 \%$. Using reported AC, sensitivity for SGA at birth was lower at $5.5 \%$.

One hundred ninety-five of the 1008 pregnancies resulted in the birth of a LGA neonate. Using EFW, 217 cases of LGA were reported by ultrasound; only 119 (54.8\%) were LGA at birth (sensitivity 61\%; PPV 54.8\%). Using reported AC, sensitivity for LGA was similar at $58.6 \%$ with a lower PPV of $42.4 \%$. 
Performance figures for the identification of SGA or LGA showed no significant differences between BMI classes. For women who had more than one third trimester ultrasound, performance was similar after two ultrasounds (data not shown); for those who had 3 ultrasounds ( $\mathrm{n}=223$ ) sensitivity for SGA using EFW rose to $18 \%$ and for LGA to $73 \%$. After 3 ultrasounds PPV for LGA at birth remained at 50\%

The median EFW percentile was higher than the birthweight percentile until the birthweight was greater than the $80^{\text {th }}$ percentile (Figure 2). Only $40 \%$ of birthweight percentiles $(405 / 1008)$ were within +/- 10 percentiles of EFW percentiles and this did not vary significantly across BMI groups ( $\mathrm{p}=0.445$ ). Of the remaining $60 \%$ of ultrasounds, $46 \%$ of EFW overestimated the birthweight by $>10$ percentiles and $14 \%$ of EFW underestimated the birthweight by $>10$ percentiles.

\section{$\underline{\text { Discussion }}$}

As the rates of maternal obesity increase, further evidence to guide management is required. With the aim of detecting the increased occurrence of abnormal fetal growth and preventing associated poor outcomes, Australian guidelines recommend performing a third trimester growth ultrasound for pregnancies complicated by obesity. ${ }^{6,7}$ Compliance with this recommendations was $93 \%$ overall, although only $80 \%$ had an ultrasound within the optimum gestational range. For women with Class II/III obesity without diabetes who had at least one ultrasound performed between $34+0$ and $36+6$ weeks, the ultrasound EFW had a sensitivity of only $8.1 \%$ for detecting birthweight below $10^{\text {th }}$ percentile (SGA) and a $61 \%$ sensitivity for detecting birthweight over $90^{\text {th }}$ percentile (LGA). All women found on ultrasound scan to have an EFW below $10^{\text {th }}$ percentile went on to deliver a SGA neonate but most SGA neonates are not detected by ultrasound. Although better at detecting LGA neonates, only $54.8 \%$ of babies predicted to be LGA will be born above the $90^{\text {th }}$ percentile. Whereas the sensitivity for detecting SGA rose slightly to $18 \%$ for women who had 3 scans, the PPV remained at $50 \%$ for detecting LGA.

We considered an ultrasound to be predictive of birthweight if the EFW percentile was within $+/-10$ of the birthweight percentile. Our study found that $40 \%$ of growth ultrasounds met this criterion and that this did not change with increasing maternal BMI. However, $46 \%$ of 
ultrasounds overestimated fetal weight by greater than $10 \%$ when compared with the eventual birthweight (BW) percentile. The median EFW percentile was higher than the actual birthweight percentile for most of the pregnancies screened. This result suggests that ultrasounds performed around 35 weeks consistently overestimates the birthweight percentile, except for the larger neonates.

Our findings are similar to a recent comparable study by Dude and colleagues looking at nulliparous women with Class II and III obesity having an ultrasound within five weeks of delivery. ${ }^{17}$ They found a higher sensitivity for detecting SGA of $26.3 \%$ but lower specificity of $85.7 \%$ and a PPV of only $38.5 \%$. They found a similar sensitivity for detecting LGA (75.3\%) and PPV of 46.2\%. Harper and colleagues reported sensitivity for SGA of $32 \%$ and LGA of $38.6 \%$ with a PPV of $71.4 \%$ for SGA and $77.1 \%$ for LGA; their population differed importantly from ours by including all classes of BMI although, similar to our study, they included women who may have had multiple scans. ${ }^{18}$

Our findings have important implications for clinical practice. For the clinician faced with a woman with a SGA fetus on ultrasound, there is a high likelihood that her baby is, indeed, small and surveillance and timing of delivery decisions can reasonably be based on that expectation. If the ultrasound suggests that the fetus is LGA, there is, approximately, a $45 \%$ chance that at delivery her baby will not be above the $90^{\text {th }}$ percentile. This is important for counselling and consideration of timing and route of delivery. When the ultrasound scan does not suggest abnormal growth, the eventual birthweight is highly variable and subsequent concerns for fetal wellbeing, such as a presentation with decreased fetal movement, should not be ignored because of an apparently reassuring fetal growth scan.

A recent Australian report suggested, in contrast to our findings, that a 36-week ultrasound scan can accurately represent birthweight. ${ }^{19}$ The difference may result from a different approach to the statistical analysis: our study used classification measurements including sensitivity, specificity, PPV and NPV. O'Brien and colleagues used association measurements and found good correlations. We analysed our data for correlations and found very similar results to O'Brien and colleagues (data not presented). In clinical practice, classification measurements, such as SGA or LGA, drive management decisions. ${ }^{20}$ Whereas there is good correlation between EFW and birthweight, the classification into SGA or LGA is poor, hindering the detection of SGA and overcalling LGA. 
Several studies report favourably on the accuracy of ultrasound scans in predicting birth weight if performed at a time close to delivery. ${ }^{8,9,11} \mathrm{We}$ are not able to assess if the discrepancy between EFW and BW in our study is the result of inaccuracy of the original ultrasound or is an effect of the time interval. In our study the ultrasounds were performed by a range of clinicians in a variety of settings, whereas most studies reporting on accuracy of ultrasound were performed by sub-specialists, often in a research environment. It is possible that the poor sensitivity for SGA is a result of late onset growth restriction, as obese women have higher rates of fetoplacental insufficiency. ${ }^{5}$ This could explain the increased rates of late third trimester stillbirth associated with obesity. ${ }^{21}$

This study has limitations resulting from the use of retrospective and secondary data. Although the hospital databases are comprehensive and widely used, there is a possibility of missing or incorrectly entered information. We have not controlled for the location of the ultrasound, experience of the sonologist, ultrasound machine used, or the formula used to calculate the EFW percentile, although a large majority (97.3\%) used the Hadlock formula. ${ }^{13}$ We have not compared our findings to women with a healthy BMI, as in an otherwise uncomplicated pregnancy, they do not currently have an indication for a growth ultrasound. Strengths of our study include the relatively large number of cases included as well as the use of classification statistics to assess the 'real world' utility of routine ultrasound scans in obese women.

Our study has identified areas for future research. While overestimation on ultrasound is consistent with previous findings, previous studies looking at accuracy of growth ultrasounds in obese women have used the EFW and actual birthweight in grams rather than as a percentile ${ }^{8-10}$ Our study questions the predictive utility of the percentiles in the current formulae used. Dudley summarized that there is no preferred method for ultrasound fetal weight estimation with further work needed to improve the universal validity and accuracy of fetal weight estimation formulae. ${ }^{22}$ Future studies are also needed to evaluate clinically important endpoints and cost-benefit analysis of different ultrasound protocols to determine if diagnostic performance is improved at later gestations.

The findings of our study question the utility of current recommendations for a routine third trimester growth scan for obese women. It is important to incorporate the poor performance 
of this scan in management decisions for, and counselling of, obese women in the late third trimester.

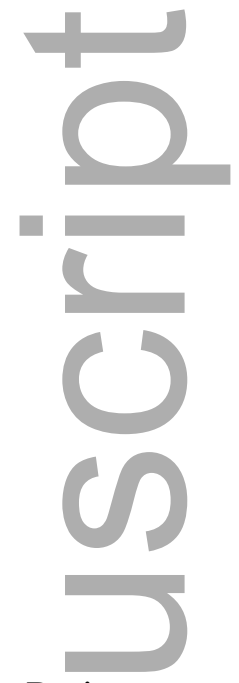

Table 1: Parity, gestational age, mean birthweight and number of ultrasounds by BMI category.

\begin{tabular}{|c|c|c|c|c|}
\hline & $\begin{array}{c}\text { All } \\
(n=1008)\end{array}$ & $\begin{array}{c}35.0-39.9 \\
\mathrm{~kg} / \mathrm{m}^{2} \\
\mathrm{n}=\mathbf{5 2 5} \\
(52.1 \%)\end{array}$ & $\begin{array}{c}40.0+\mathrm{kg} / \mathrm{m}^{2} \\
\mathrm{n}=483 \\
(47.9 \%)\end{array}$ & p-value \\
\hline \multicolumn{5}{|l|}{ Parity: } \\
\hline Nulliparous & $309(30.7 \%)$ & $169(32.2 \%)$ & $140(29.0 \%)$ & \\
\hline Multiparous & $658(65.3 \%)$ & $334(63.6 \%)$ & $324(67.1 \%)$ & \\
\hline $\begin{array}{r}\text { Grand } \\
\text { Multiparous }\end{array}$ & $41(4.1 \%)$ & $22(4.2 \%)$ & $19(3.9 \%)$ & 0.510 \\
\hline One & $382(38.0 \%)$ & $254(48.4 \%)$ & $128(26.6 \%)$ & \\
\hline Two & 401 (39.9\%) & $187(35.6 \%)$ & $214(44.5 \%)$ & \\
\hline$\geq$ Three & $223(22.2 \%)$ & $84(16.0 \%)$ & $139(28.9 \%)$ & $<0.001$ \\
\hline $\begin{array}{l}\text { Mean Gestational } \\
\text { age at delivery } \\
\text { (weeks) (SD) }\end{array}$ & $39.24(1.10)$ & $39.35(1.1)$ & $39.1(1.1)$ & 0.002 \\
\hline
\end{tabular}




\begin{tabular}{|c|c|c|c|c|}
\hline $\begin{array}{c}\text { Mean Birthweight } \\
\text { (grams) (SD) }\end{array}$ & $3546(489)$ & $3545(493)$ & $3548(485)$ & 0.905 \\
\hline & All women with BMI & Women with BMI & Women with BMI $\geq 40.0$ \\
& $\geq 35.0 \mathrm{~kg} / \mathrm{m}^{2}$ & $35.0-39.9 \mathrm{~kg} / \mathrm{m}^{2}$ & $\mathrm{~kg} / \mathrm{m}^{2}$ \\
$(\mathrm{n}=1008)$ & $(\mathrm{n}=525)$ & $483)$ \\
\hline
\end{tabular}

\begin{tabular}{|c|c|c|c|c|}
\hline $\begin{array}{c}\text { Mean Birth } \\
\text { Percentile (SD) }\end{array}$ & $58(30)$ & 57 (30) & $59(30)$ & 0.251 \\
\hline $\begin{array}{c}\text { SGA }\left(\text { BW }<10^{\text {th }}\right. \\
\text { percentile })\end{array}$ & $74(7.3 \%)$ & $46(8.9 \%)$ & $28(5.8 \%)$ & 0.071 \\
\hline $\begin{array}{c}\text { LGA }\left(B W>90^{\text {th }}\right. \\
\text { percentile })\end{array}$ & $195(19.3 \%)$ & $93(17.7 \%)$ & $102(21.2 \%)$ & 0.172 \\
\hline
\end{tabular}

Table 2: Diagnostic performance of third trimester ultrasound (one or more) in the obese population. 


\begin{tabular}{|c|c|c|c|}
\hline $\begin{array}{l}\text { Large for gestational } \\
\text { age (EFW >90\%) }\end{array}$ & & & \\
\hline Screen positive & 217 & 102 & 115 \\
\hline $\begin{array}{l}\text { True positive } \\
(\mathrm{BW}>90 \%)\end{array}$ & 119 & 59 & 60 \\
\hline Sensitivity & $61.0 \%(53.8-67.8 \%)^{\dagger}$ & $63.4 \%(52.7-73.0 \%)$ & $58.8 \%(48.6-68.3 \%)$ \\
\hline Specificity & $87.9 \%(85.5-90.1 \%)$ & $90.0 \%(86.7-92.6 \%)$ & $85.6 \%(81.5-88.6 \%)$ \\
\hline Positive predictive value & $54.8 \%(48.0-61.5 \%)$ & $57.8 \%(47.8-67.4 \%)$ & $52.2 \%(42.7-61.5 \%)$ \\
\hline Negative predictive value & $90.4 \%(88.1-92.3 \%)$ & $91.9 \%(88.8-94.3 \%)$ & $88.6 \%(84.8-91.6 \%)$ \\
\hline $\mathrm{AUC}^{\ddagger}$ & $0.86(0.84-0.89)$ & $0.88(0.84-0.91)$ & $0.84(0.81-0.88)$ \\
\hline \multicolumn{4}{|l|}{$\begin{array}{l}\text { Small for gestational age } \\
(\text { EFW }<10 \%)\end{array}$} \\
\hline Screen positive & 6 & 5 & 1 \\
\hline $\begin{array}{l}\text { True positive } \\
(\mathrm{BW} \leq 10 \%)\end{array}$ & 6 & 5 & 1 \\
\hline Sensitivity & $8.1 \%(3.3-17.4 \%)$ & $10.9 \%(4.1-24.4 \%)$ & $3.6 \%(1.9-20.2 \%)$ \\
\hline Specificity & $100 \%(99.5-100 \%)$ & $100 \%(99.0-100 \%)$ & $100 \%(98.9-100 \%)$ \\
\hline Positive predictive value & $100 \%(51.8-100 \%)$ & $100 \%(46.3-100 \%)$ & $100 \%(5.4-100 \%)$ \\
\hline Negative predictive value & $93.2 \%(91.4-94.7 \%)$ & $92.0 \%(89.4-94.2 \%)$ & $94.4 \%(91.8-96.2 \%)$ \\
\hline $\mathrm{AUC}^{\ddagger}$ & $0.12(0.09-0.16)$ & $0.10(0.06-0.14)$ & $0.15(0.09-0.216)$ \\
\hline \multicolumn{4}{|l|}{$\begin{array}{l}\text { Large for gestational } \\
\text { age }(\mathrm{AC}>90 \%))\end{array}$} \\
\hline Screen positive & 264 & 123 & 141 \\
\hline $\begin{array}{l}\text { True positive } \\
(\mathrm{BW}>90 \%)\end{array}$ & 112 & 47 & 65 \\
\hline Sensitivity & $58.6 \%(51.3-65.6 \%)$ & $52.8 \%(41.9-63.4 \%)$ & $63.7 \%(53.5-72.8 \%)$ \\
\hline Specificity & $80.8 \%(77.8-83.4 \%)$ & $81.9 \%(77.9-85.5 \%)$ & $79.4 \%(74.9-83.4 \%)$ \\
\hline Positive predictive value & $42.4 \%(36.4-48.6 \%)$ & $38.2 \%(29.7-47.4 \%)$ & $46.1 \%(37.7-54.7 \%)$ \\
\hline Negative predictive value & $89.0 \%(86.4-91.1 \%)$ & $89.2 \%(85.5-92.0 \%)$ & $88.9 \%(84.8-91.9 \%)$ \\
\hline $\mathrm{AUC}^{\ddagger}$ & $0.82(0.79-0.85)$ & $0.82(0.77-0.86)$ & $0.82(0.78-0.86)$ \\
\hline \multicolumn{4}{|l|}{$\begin{array}{l}\text { Small for gestational age } \\
(\mathrm{AC}<10 \%))\end{array}$} \\
\hline Screen positive & 7 & 6 & 1 \\
\hline $\begin{array}{l}\text { True positive } \\
(\mathrm{BW} \leq 10 \%)\end{array}$ & 4 & 4 & 0 \\
\hline
\end{tabular}




\begin{tabular}{|l|l|l|l|}
\hline Sensitivity & $5.5 \%(1.8-14.2 \%)$ & $8.8 \%(6.6-11.7 \%)$ & $0 \%(0-15.0 \%)$ \\
\hline Specificity & $99.7 \%(98.9-99.9 \%)$ & $99.6 \%(98.3-99.9 \%)$ & $99.8 \%(98.5-99.9 \%)$ \\
\hline Positive predictive value & $57.1 \%(20.2-88.2 \%)$ & $66.6 \%(24.1-94.0 \%)$ & $0 \%(0-94.5 \%)$ \\
\hline Negative predictive value & $92.9 \%(91.0-94.4 \%)$ & $91.9 \%(89.1-94.0 \%)$ & $94.0 \%(91.4-95.9 \%)$ \\
\hline AUC ${ }^{\ddagger}$ & $0.15(0.11-0.19)$ & $0.11(0.07-0.15)$ & $0.21(0.13-0.29)$ \\
\hline
\end{tabular}

†Data are presented as \% (95\% confidence interval) †AUC: area under curve

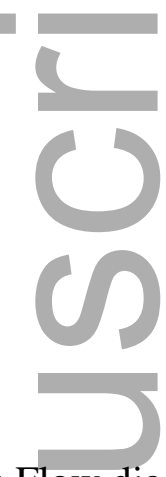

Figure 1: Flow diagram of patients included for analysis

Figure 2: Boxplot showing the range of the Estimated Fetal Weight percentiles for each decile of Birthweight

\section{$\underline{\text { References }}$ \\ $\underline{\mathbf{S}}$}
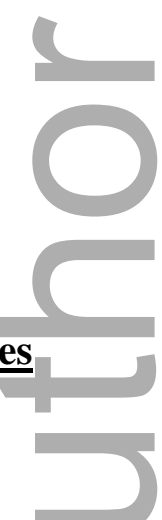

1. Dutton H, Borengasser SJ, Gaudet LM, Barbour LA, Keely EJ. Obesity in Pregnancy: Optimizing Outcomes for Mom and Baby. Med Clin North Am. 2018;102(1):87-106.

2. Cunningham CE, Teale GR. A profile of body mass index in a large rural Victorian obstetric cohort. Med J Aust. 2013;198(1):39-42.

3. Australian Institute of Health and Welfare. Australia's mothers and babies 2017-in brief. Perinatal statistics series no. 35. Cat. no. PER 100. Canberra AIHW;2019. 
4. D’Souza R, Horyn I, Pavalagantharajah S, Zaffar N, Jacob C-E. Maternal body mass index and pregnancy outcomes: a systematic review and metaanalysis. American Journal of Obstetrics \& Gynecology MFM. 2019;1(4):100041.

5. O'Brien C M, Poprzeczny A, Dodd JM. Implications of maternal obesity on fetal growth and the role of ultrasound. Expert Rev Endocrinol Metab. 2017;12(1):45-58.

6. RANZCOG Statement: Management of Obesity in Pregnancy 2017. https://ranzcog.edu.au/RANZCOG_SITE/media/RANZCOGMEDIA/Women\%27s\%20Health/Statement\%20and\%20guidelines/ClinicalObstetrics/Management-of-obesity-(C-Obs-49)-Review-March2017.pdf?ext=.pdf\#: :text=You\%20will\%20be\%20given\%20a,BMI\%20is\%2030\%20 or\%20higher.

7. Better Safer Care, Victoria: Obesity during pregnancy, birth and postpartum. 2018. https://www.bettersafercare.vic.gov.au/resources/clinical-guidance/maternityehandbook/obesity-during-pregnancy-birth-and-postpartum.

8. Al-Obaidly S, Al-Ibrahim A, Saleh N, Al-Belushi M, Al-Mansouri Z, Khenyab N. Third trimester ultrasound accuracy and delivery outcome in obese and morbid obese pregnant women. J Matern Fetal Neonatal Med. 2019;32(8):1275-1279.

9. Gonzalez MG, Reed KL, Center KE, Hill MG. Does Maternal Body Mass Index Have an Effect on the Accuracy of Ultrasound-Derived Estimated Birth Weight?: A Retrospective Study. J Ultrasound Med. 2017;36(5):1009-1014.

10. Aksoy H, Aksoy Ü, Karadağ Ö, Yücel B, Aydın T, Babayiğit MA. Influence of maternal body mass index on sonographic fetal weight estimation prior to scheduled delivery. J Obstet Gynaecol Res. 2015;41(10):1556-1561.

11. Manzanares S, Gonzalez-Escudero A, Gonzalez-Peran E, Lopez-Criado M, Pineda A. Influence of maternal obesity on the accuracy of ultrasonography birth weight prediction.J Matern Fetal Neonatal Med. 2019:1-6.

12. Martinez CA. The Ultrasound evaluation of the diabetic pregnancy. In: E ML, ed. Diabetes in Pregnancy. Springer; 2018:163-181.

13. Hadlock FP, Harrist RB, Sharman RS, Deter RL, Park SK. Estimation of fetal weight with the use of head, body, and femur measurements--a prospective study. Am J Obstet Gynecol. 1985;151(3):333-337.

14. Perintal Institute: Generic Birthweight Centile Calculator. www.pi.nhs.uk/download/graw/GRAWCentv1.xls. Published Oct 2010. Accessed 10 November, 2018. 
15. Dobbins TA, Sullivan EA, Roberts CL, Simpson JM. Australian national birthweight percentiles by sex and gestational age, 1998-2007. Med J Aust. 2012;197(5):291-294.

16. Bujang MA, Adnan TH. Requirements for Minimum Sample Size for Sensitivity and Specificity Analysis. J Clin Diagn Res. 2016;10(10):YE01-YE06.

17. Dude AM, Davis B, Delaney K, Yee LM. Identifying fetal growth disorders using ultrasound in obese nulliparous women. J Matern Fetal Neonatal Med. 2019:1-6.

18. Harper LM, Jauk VC, Owen J, Biggio JR. The utility of ultrasound surveillance of fluid and growth in obese women. Am J Obstet Gynecol. 2014;211(5):524 e521-528.

19. O'Brien CM, Louise J, Deussen A, Dodd JM. In overweight and obese women, fetal ultrasound biometry accurately predicts newborn measures. Aust N Z J Obstet Gynaecol. 2020;60(1):101-107.

20. Feng Z. Classification versus association models: should the same methods apply? Scand J Clin Lab Invest Suppl. 2010;242:53-58.

21. Yao R, Ananth CV, Park BY, Pereira L, Plante LA, Perinatal Research C. Obesity and the risk of stillbirth: a population-based cohort study. Am J Obstet Gynecol. 2014;210(5):457 e451-459.

22. Dudley NJ. A systematic review of the ultrasound estimation of fetal weight. Ultrasound Obstet Gynecol. 2005;25(1):80-89.

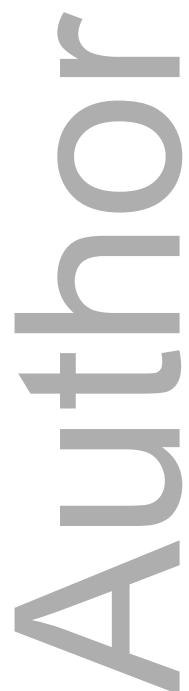


Figure 1: Flow diagram of patients included for analysis

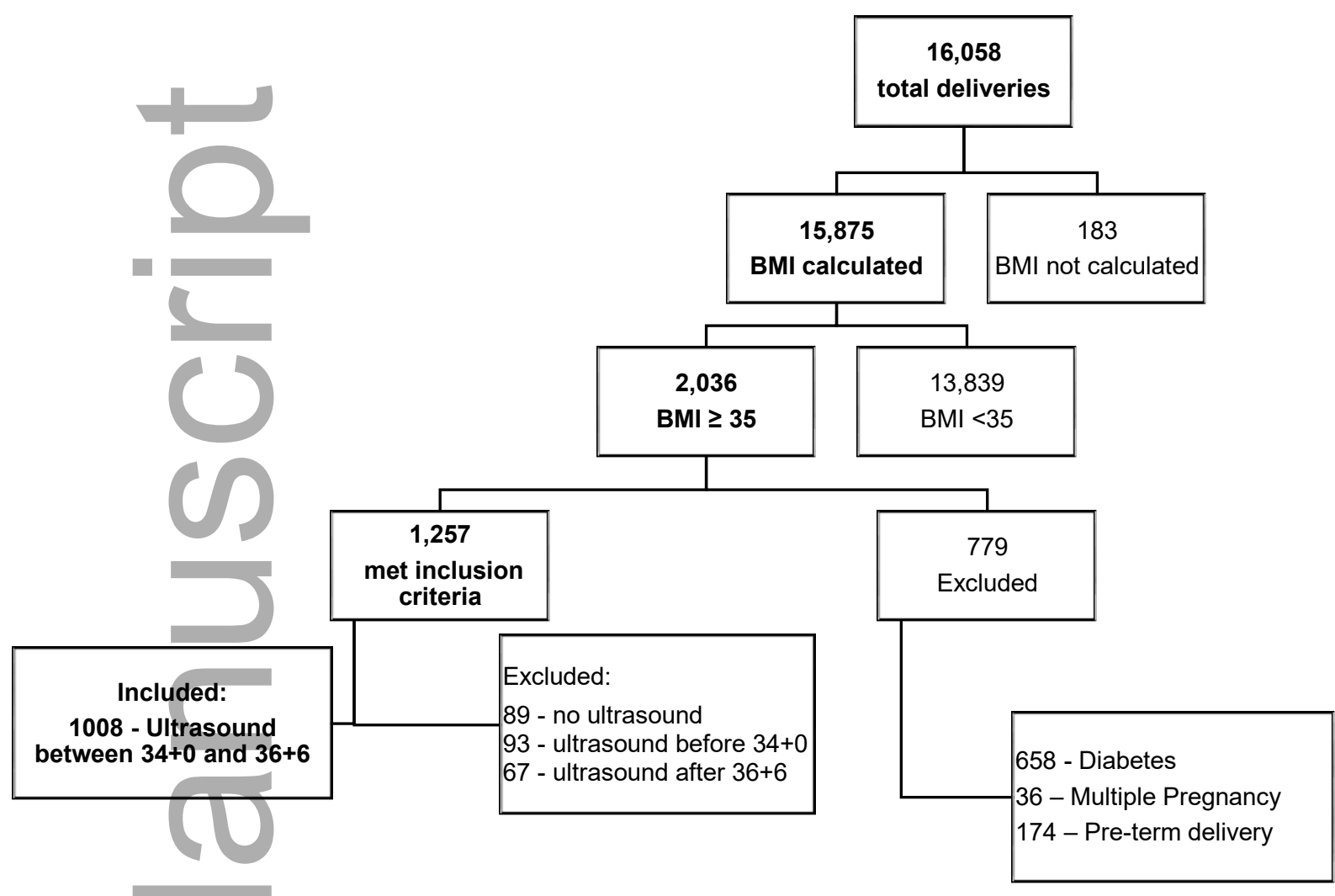

This article is protected by copyright. All rights reserved 
Figure 2: Boxplot showing the range of the Estimated Fetal Weight percentiles for each decile of Birthweight
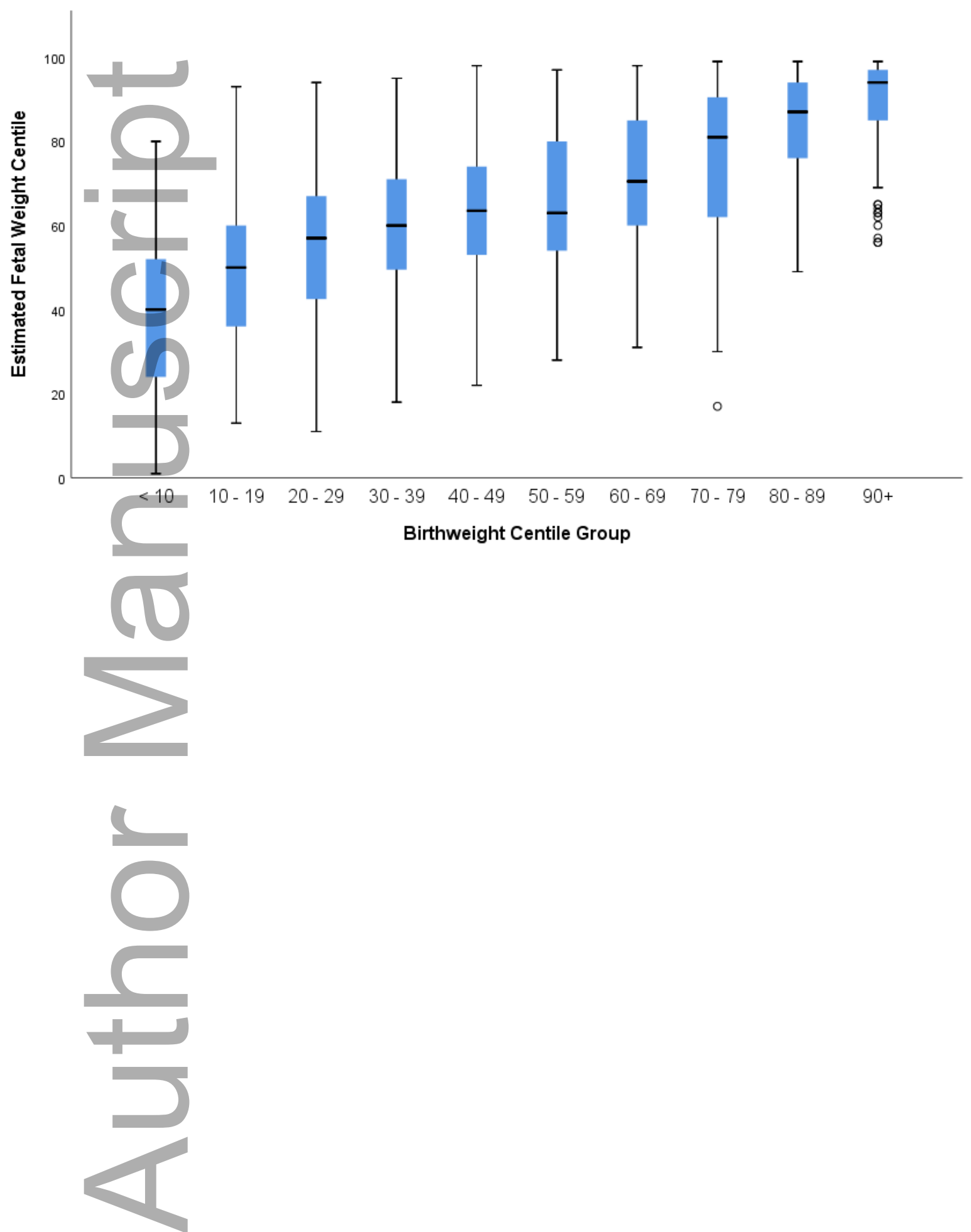

This article is protected by copyright. All rights reserved 


\section{University Library}

\section{- M I N E R VA}

\section{A gateway to Melbourne's research publications}

Minerva Access is the Institutional Repository of The University of Melbourne

\section{Author/s:}

Neel, A;Cunningham, CE;Teale, GR

Title:

A routine third trimester growth ultrasound in the obese pregnant woman does not reliably identify fetal growth abnormalities: A retrospective cohort study

Date:

2020-10-24

\section{Citation:}

Neel, A., Cunningham, C. E. \& Teale, G. R. (2020). A routine third trimester growth ultrasound in the obese pregnant woman does not reliably identify fetal growth abnormalities: A retrospective cohort study. AUSTRALIAN \& NEW ZEALAND JOURNAL OF OBSTETRICS \& GYNAECOLOGY, 61 (1), pp.116-122. https://doi.org/10.1111/ajo.13256.

Persistent Link:

http://hdl.handle.net/11343/276479 